\title{
The German Evidence-Based Child Protection Guideline - Imaging in Suspected Child Abuse
}

\section{Die deutsche S3-Kinderschutzleitlinie - Bildgebung bei Verdacht auf Kindesmisshandlung}

Authors

Markus Born ${ }^{1}$, Frauke Schwier ${ }^{2}$, Brigitte Stoever ${ }^{3}$, Hans-Joachim Mentzel' ${ }^{4}$, Jürgen Freiberg ${ }^{5}$

Affiliations

1 Radiology, Pediatric Radiology, University of Bonn, Germany

2 Children's Hospital, University of Bonn, Germany

3 Radiology, Charité Medical Faculty Berlin, Germany

4 Paediatric Radiology, Institute for Diagnostic and Interventional Radiology, Jena, Germany

5 Patient Management, University of Bonn, Germany

Key words

infants injuries, child abuse, guideline, children injuries, skeletal survey

received 31.07.2019

accepted 13.09.2019

Bibliography

DOI https://doi.org/10.1055/a-1019-8018

Published online: 20.11.2019

Fortschr Röntgenstr 2020; 192: 343-348

(c) Georg Thieme Verlag KG, Stuttgart · New York

ISSN 1438-9029

Correspondence

Dr. Markus Born

Radiology, Pediatric Radiology, University of Bonn,

Mandatsträger der GPR, Venusberg - Campus 1, 53127 Bonn, Germany

Tel.: ++ 49/2 28/28733225

Fax: $++49 / 228 / 28733566$

mark.born@ukbonn.de

\section{ABSTRACT}

Aim Development of a fully evidence-based guideline including all aspects of child abuse.

Methods In a case-based procedure, 144 primary PICO questions were generated from 476 presented cases of child abuse. Literature research was performed in 5 databases (Pubmed, CINHAL, Embase, Psyclnfo, Eric) and in the Cochrane Library. The literature was evaluated according to SIGN and AGREE II.
Results 137 recommendations were developed. Those related to imaging procedures are presented and discussed in this article.

Conclusion The first fully evidence-based German guideline concerning all aspects of child abuse has been established. For imaging, several relevant new approaches have been proposed.

\section{Key Points:}

- The average radiation exposure is significantly reduced for the whole group of examined children.

- The pelvic view and lateral spine are no longer basic views of the skeletal survey but are only performed additionally in the case of a positive survey.

- Oblique views and a follow-up survey are performed in the case of a negative skeletal survey and ongoing suspicion of child abuse.

\section{Citation Format}

- Born M, Schwier F, Stoever B et al. The German EvidenceBased Child Protection Guideline - Imaging in Suspected Child Abuse. Fortschr Röntgenstr 2020; 192: 343-348

\section{ZUSAMMENFASSUNG}

Ziel Erstellung einer interdisziplinären, evidenzbasierten Leitlinie (S3) zur Vorgehensweise bei Verdacht auf Kindesmisshandlung.

Methoden Fallbasierte Leitlinienerstellung. Extraktion von 144 primären PICO-Fragen aus 476 durch Fachgesellschaften eingereichten Kinderschutzfällen. Die Literaturrecherche erfolgte in 5 Datenbanken (Pubmed, CINHAL, Embase, Psyclnfo, Eric) und in der Cochrane-Library, die Literaturbewertung nach SIGN und AGREE II.

Ergebnisse Es wurden 137 Handlungsempfehlungen erarbeitet. Die die Bildgebung betreffenden Empfehlungen sollen hier vorgestellt und diskutiert werden.

Schlussfolgerung Es liegt erstmals eine vollständig evidenzbasierte deutsche Leitlinie zur Vorgehensweise bei Kindesmisshandlung vor. Für die Bildgebung ergeben sich einige bedeutsame Neuerungen. 


\section{Introduction}

42.435 cases of violence against children under the age of 14 years were recorded in 2016 in Germany [1]. A high number of unreported cases can be assumed. Since physical abuse, particularly of infants, can have serious consequences for the health of the affected children including severe injury-related mental defects with severe developmental disorders and lifelong need of care or even death, imaging is essential for the clarification of physical abuse. Imaging must detect injuries requiring treatment quickly and fully in an acute situation. Since the constellations of abuse are typically repeated in the environment of these children, repetitive abuse often occurs. Therefore, imaging must also detect prior injuries that have become clinically occult at the time of presentation due to the healing process. Imaging thus ideally prevents revictimization of these children with escalation of the level of violence. Imaging findings are often an important basis for the decision of authorities to protect a child, possibly resulting in removal of the child from the family. Imaging also provides an important basis for decision for subsequent legal proceedings.

Therefore, the selection and implementation of imaging in suspected child abuse is extremely important for various reasons. The interdisciplinary S3 Child Protection Guideline includes evidence-based recommendations for all aspects of child protection ${ }^{1}$. The imaging-related recommendations in this guideline are presented in the following.

\section{Methods}

The guideline was created under the auspices of the German Society for Child Protection in Medicine (DGKIM) with the collaboration of 79 professional societies, organizations, and federal ministries and with the financial support of the german Federal Minstry of Health. The "Gesellschaft für Pädiatrische Radiologie" (GPR) is one of the professional societies publishing the Child Protection Guideline.

Due to its complexity, the guideline was developed, in coordination with the Association of the Scientific Medical Societies in Germany (Arbeitsgemeinschaft der Wissenschaftlichen Medizinischen Fachgesellschaften e. V., AWMF) using a casebased approach [2]. From 476 child abuse cases presented by the professional societies, 20 case vignettes were created and 144 primary $\mathrm{PICO}^{2}$ questions [3] were generated. These questions were consolidated into 33 PICO questions and literature research was performed in 5 databases (Pubmed, CINHAL, Embase, Psyclnfo, Eric) and in the Cochrane Library. The literature was evaluated by two members of the Child-Protection-Guideline's office respectively according to SIGN [4] and AGREE II [5]. Under consideration of the four existing guidelines on imaging in suspicion of child abuse, the recommendations were developed in a Delphi procedure with a subsequent consensus conference [6-9].

1 In the german classification systems for guidelines "S3" significates "fully evidence based", i. e. the highest possible level of evidence.

$2 \mathrm{PICO}=$ Patient Intervention Comparison Outcome.

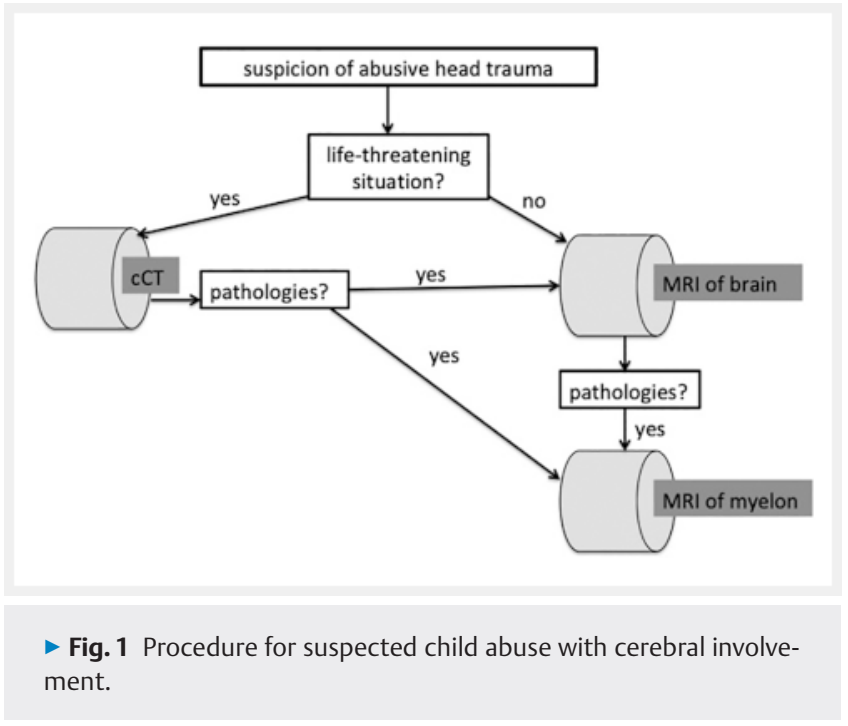

\section{Results}

The S3 Child Protection Guideline was published by the AWMF on 2/5/2019 with registration number 027-069 [10]. The recommendations regarding imaging can be divided into recommendations for examining the central nervous system, the skeleton, and the inner abdominal and thoracic organs.

\section{Examination of the central nervous system in suspected child abuse}

MRI is the modality with the highest sensitivity and specificity to detect injuries of the central nervous system (CNS) also in the case of suspected abusive head trauma. In accordance with the procedure for accident-related trauma, cranial CT (CCT) should only be performed in the case of acute, life-threatening risk to the child. Ultrasound of the brain while the fontanelle is still open has insufficient diagnostic significance and therefore SHOULD not be the only imaging examination of the CNS performed in suspicion of abusive head trauma (no. 76) [11].

The guideline recommends the following procedure (see $>$ Fig. 1):

- MRI of the brain SHOULD be performed in the case of suspicion of abusive head trauma (no. 73). If signs of abuse are found, MRI of the spine SHOULD be performed additionally (no. 73).

- If the child is in a life-threatening situation, a cranial CT examination SHOULD be performed (no. 74). If signs of injury are seen, MRI of the head and spine SHOULD also be performed, after stabilization of the child (no. 75).

- The MRI examinations SHOULD include diffusion weighted imaging (DWI). Susceptibility weighted imaging is also useful but could not be included in the guideline as a (strong) recommendation because of the lack of evidence. It makes sense for MRI of the brain to be followed directly by MRI of the spine in the case of pathological findings to avoid subjecting the child to a second examination procedure including transportation and potentially anesthasia. Therefore an experienced (pediatric) radiologist should be present during the MRI examination and the corresponding coil for the examination of the spine should already be selected and activated during examination of the skull. 
Combinations of at least two of the following symptoms are specified as constellations justifying the suspicion of abuse (no. 81):

- Non-accidental injury and a questionable anamnesis

- Subdural hematoma

- Cerebral diffusion impairment

- Skull fracture with or without intracranial injury

- Rib fracture(s)

- (Metaphyseal) fracture/s of the long bones

- Brain seizure

- Apnea

If two or more of the specified symptoms apply, further imaging SHOULD be performed. If cerebral or spinal imaging shows pathological changes (e.g. subdural hematoma or restricted diffusion) consistent with physical abuse, further diagnostic imaging, particularly a skeletal survey, SHOULD be performed (no. 79).

\section{Examination of the skeleton in suspected child abuse}

\section{Skeletal survey}

To perform radiological examination, there should be founded suspicion or evidence of physical abuse of the child in question or evidenceof abuse of another child in the same household. An interdisciplinary team including at least two physicians should determine whether these requirements have been met. The signs of abuse listed in no. 81 provide a reference point.

The guideline defines a skeletal survey to evaluate skeletal involvement in the case suspected or proven physical abuse. This differs from the screening recommended by the previous german AWMF-guidline in multiple ways. On the one hand, pelvic and spinal X-rays with high radiation exposure are no longer indispensable in the skeletal survey. Both X-rays are omitted if the skeletal survey does not show any fractures. They SHOULD be acquired as supplementary images only in the case of one or more fractures (strong recommendation). On the other hand, oblique images of the thorax in addition to the ap view SHOULD be acquired if no fractures are seen in the skeletal survey. To date, oblique images of the thorax have been optional in the German guideline. As a third major difference, the skeletal survey SHOULD be repeated after 11 to 14 days (except for the skull X-rays) in the case of a negative finding but continued suspicion of child abuse. This also was previously optional. The skeletal survey procedure described here is outlined in > Fig. 2.

According to the guideline, infants and toddlers up to 24 months SHOULD undergo a skeletal survey in the case of suspected abuse (no.83) as also recommended in the previous German $\mathrm{S} 1$ guideline and in the currently valid guidelines of other countries. However, there is evidence that a skeletal survey can also be useful in children older than 24 months [12]. In a comprehensive study including 2036 children who received a skeletal survey due to suspicion of abuse, Lindberg et al. report that occult fractures were detected by skeletal survey in $15.2 \%$ (57/374) of children from 12 to 24 months of age and in $15.9 \%$ (33/207) of children from 24 to 36 months of age [12].

Therefore, the age range for skeletal survey has been expanded in the present new S3 guideline to 36 months in certain cases, e. $g$. , in the case of proven fractures, brain injury, thermal injuries,

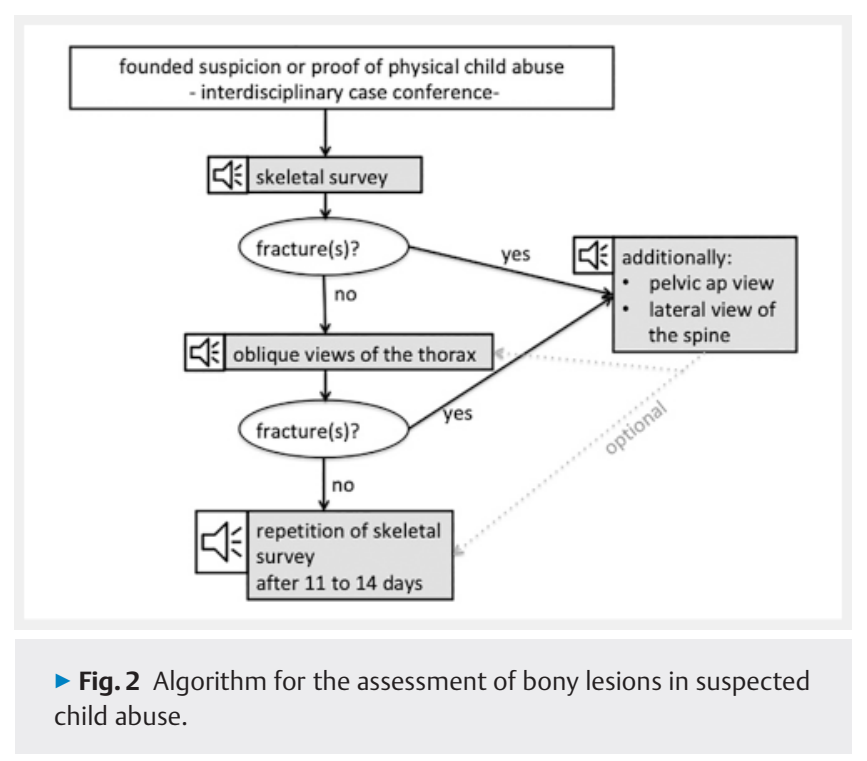

or abuse-related hematomas (nos. 67, 85) with the level of recommendation being reduced to "MIGHT" here.

Primary skeletal survey includes the following views (no. 82,

- Table 1):

- Skull ap and lateral

- Thorax ap

- Both upper arms, lower arms, thighs, lower legs, hands, and feet ap

This makes a total of $15 \mathrm{X}$-rays. The guideline allows the upper and lower leg as well as the upper and lower arm to be visualized on a single image in small children.

Both hands and both feet can also be visualized next to one another on one X-ray.

In the guideline, the GPR states that fractures and questionable findings are to be visualized by an additional $X$-ray on a second plane.

\section{Fractures}

The suspicion of physical abuse is often founded on the diagnosis of a fracture without a witnessed adequate accidental trauma. In the case of multiple fractures, doubtful anamnesis or a lack of witnessed accidental trauma, the suspicion of abuse SHOULD be persued regardless of the child's age (no. 89). However, also certain single fractures like skull, rib, spinal, and pelvic fractures and, in the case of extremity fractures, metaphyseal fractures can be an indication for further diagnostics (nos. 90-99). Since the referenced literature serves as evidence for the recommendations in the guideline, the recommendations must take the age groups of the children examined in the individual studies into consideration. There is no study-based evidence for other age groups. As a result, different ages are specified for the indication of further diagnostic procedures for different types of fracture in the guideline. If the age of a child in a case of suspected abuse is outside the age range specified here, the further course of action is to be determined on an individual and interdisciplinary basis by at least two physicians. The age and developmental stage of the child SHOULD be taken into consideration (no. 88). 
- Table 1 The table indicates which views are included in a skeletal survey. The guideline allows, in small children, to capture and upper arm and forearm as well as upper leg and thigh on one $\mathrm{x}$-ray.

\begin{tabular}{|l|l|}
\hline & \multicolumn{2}{|c|}{ skeletal survey } \\
\hline body part & beam path \\
\hline skull & ap and lateral \\
\hline thorax & ap \\
\hline all four extremities & \\
\hline upper arm/thigh & ap \\
\hline forearm/lower leg & ap \\
\hline hand/foot & ap \\
\hline
\end{tabular}

\section{Siblings}

In the case of physical abuse of a child, a skeletal survey of siblings younger than two years or other children up to two years old living in the same household MIGHT be performed (no. 86). In the case of twins or multiples living in the same household, a skeletal survey SHOULD be performed (no. 87). According to Lindberg, abuse of siblings or another child in the same household as an abused child could be detected in $11.9 \%(16 / 134)$ of examined cases, while the rate increased to $56 \%(9 / 16)$ in twins/multiples. This explains the different recommendation levels of these two recommendations [13-15].

\section{Scintigraphy}

Although literature provides evidence that skeletal scintigraphy and a skeletal survey can be used complementary to detect abuse-related fractures, skeletal scintigraphy is not recommended in the guideline due to the associated radiation exposure and the lack of specificity in the region of growth plates (no. 72).

\section{Whole-body MRI}

The sensitivity of whole-body MRI to detect abuse-specific rib and metaphyseal fractures is low $[16,17]$, on the other hand its sensitivity to detect traumatic bone marrow edema is high. A recommendation for the use of whole-body MRI to search for fractures was not made.

\section{Examination of visceral organs in suspected child abuse}

If injuries to internal organs in children up to 48 months are found without a witnessed accidental trauma, the suspicion of physical abuse SHOULD be persued (no. 100) [13].

There is insufficient evidence which examination modality shall be used to detect visceral injuries caused by child abuse. Therefore, the guideline does not include recommendations in this regard. Consequently, the examination modality must be selected on an individual basis. The primary modality for abdominal imaging of children in Europe, and in Germany in particular, is sonography. However, for the clarification of thoracic, particularly pul- monary injuries, computed tomography is the primary imaging method in the acute situation also in Germany. There are no comparative studies on the sensitivity or diagnostic value of ultrasound and computed tomography in abdominal imaging of children for suspected child abuse. The diagnostic value of wholebody MRI in this regard has also not been sufficiently evaluated.

\section{Conclusion}

The S3 Child Protection Guideline provides dedicated, evidencebased recommendations in the case of suspected physical child abuse. A short version and long version are available on the website of the AWMF (Association of the Scientific Medical Societies in Germany). A novelty as compared to the preceding german S1 guideline as well as to the guidelines of other countries is the abandonment of the pelvic view and the lateral view of the spine if no fracture is detected on the other images of a skeletal survey. The strong recommendation to acquire oblique views of the thorax and to repeat the skeletal survey after 11-14 days in the case of a negative first survey but persistent founded suspicion of physical abuse is also new. On the whole, the new skeletal survey algorithm reduces the previously necessary radiation dose significantly in cases in which no fracture is present. The guideline explains the significance of MRI for this sensitive issue and provides recommendations regarding the dedicated approach in CNS injuries and any necessary expansion of imaging to include the spinal axis. CCT is reserved for the acute situation.

\section{Discussion}

The abandonment of the pelvic view and the lateral view of the spine in the skeletal survey is supported by the literature. Spinal and pelvic fractures require significant force. They are therefore almost never seen as isolated and occult fractures in a skeletal survey [18-20]. According to the literature, these two X-rays comprise almost $75 \%$ of the radiation dose of a skeletal survey [21]. By dispensing with these two X-rays, the majority of children undergoing skeletal survey without detection of a fracture experiences therefore a significantly reduced radiation dose. This dose reduction is not negated by the additional acquisition of oblique views of the thorax since an $\mathrm{X}$-ray of the thorax requires a significantly lower dose than an X-ray of the pelvis or a lateral view of the spine. Supplementary oblique views and repetition of the skeletal survey in the case of a negative survey are justified in light of the rate of rib fractures in child abuse and the possible consequences of undetected abuse for the affected child. As a general requirement for performing imaging, founded suspicion of physical abuse must be determined by an interdisciplinary team, e. g. a child protection group. According to the literature analysis by the ROCPH (Royal College of Paediatrics and Child Health), the sensitivity for the detection of rib fractures is increased by up to $17 \%$ by additional oblique views [14]. According to a meta-analysis by Maguire, new fractures were found by repeating the skeletal survey in $8.4 \%$ to $37.6 \%$ of cases and according to Harper (also meta-analysis) new fractures could be detected by a second skeletal survey in $8 \%$ to $28 \%$ of cases. $7.1 \%$ of children with rib frac- 
tures detected in the second skeletal survey had an unremarkable finding in the first survey [13, 22, 23].

In light of the impact that skeletal survey could have on affected children and their families, the GPR as one of the co-publishers of the S3 Child Protection Guideline recommends a double reading of the skeletal survey by two pediatric radiologists or radiologists experienced in diagnosing child abuse. The importance of a specialization in pediatric radiology is described in the literature [24]. Pediatric radiologists with the necessary qualifications are available and can be inquired about at the responsible state medical chamber or on the homepage of the GPR.

The recommended age for skeletal survey in cases of suspected abuse is restricted to 24 or 36 months. Since a guideline can only provide general recommendation and in each case a decision to which extend guideline recommendations are to be followed is to be made on an individual basis, the literature cited above [12] allows a skeletal survey to also be performed after the age of 3 years given a corresponding constellation. However, this decision should be made on an interdisciplinary basis.

\section{Comments}

The words SHOULD and MIGHT are written in all caps and bold when they reflect the level of a recommendation.

\section{CLINICAL RELEVANCE}

- In the case of suspected child abuse with cerebral involvement, MRI of the brain is mandatory and is to be supplemented by MRI of the spine in the case of pathological findings (strong recommendation).

- X-rays of the spine and pelvis are no longer included in the primary skeletal survey and are only acquired on a supplementary basis in the case of fractures.

- Oblique views of the thorax SHOULD be obtained if there is founded suspicion of abuse but no fracture can be detected in the skeletal survey.

- The skeletal survey (without skull X-rays) SHOULD be repeated after 11 to 14 days if no fractures can be detected but there is still founded suspicion of child abuse.

\section{Conflict of Interest}

The authors declare that they have no conflict of interest.

\section{References}

[1] Polizeiliche Kriminalstatistik, 2.4.2019. Bundesrepublik Deutschland Jahrbuch 2018; Band 2 - Opfer; 66. Ausgabe, V 1.0. Im Internet: https://www.bka.de/DE/Aktuellelnformationen/StatistikenLagebilder/ PolizeilicheKriminalstatistik/PKS2018/pks2018_node.html;jsessionid= F145661BECE06BA633877F0E8AF760F9.live2291 (“Datenlizenz Deutschland - Namensnennung - Version 2.0", Lizenztext unter www.govdata.de/dl-de/by-2-0); Stand 15.7.2019
[2] Deutsche Gesellschaft für Kinderschutz in der Medizin (DGKiM). Im Internet: www.kinderschutzleitlinie.de; Stand: 15.7.2019

[3] University of Illinois at Chicago's Library of the Health Sciences at Peoria. Im Internet: https://researchguides.uic.edu/ebm; Stand 15.7.2019

[4] Guidelines in Praxis. Im Internet: https://www.guidelinesinpractice.co. uk/the-scottish-intercollegiate-guidelines-network-sign-/305547.arti cle; Stand 15.7.2019

[5] Browers MC, Kho ME, Browman GP et al. AGREE II: advancing guideline development, reporting and evaluation in health care. CMAJ 2010; 182 (18): E839-E842. doi:10.1503/cmaj.090449

[6] American College of Radiology. ACR-SPR practice guideline for skeletal surveys in children. 2011. Im Internet: https://www.acr.org/-/media/ ACR/Files/Practice-Parameters/Skeletal-Survey.pdf; Stand 15.7.2019

[7] The Royal College of Radiologists, the Royal College of Paediatrics and Child Health. Standards for radiological investigations of suspected nonaccidental injury. London: RCR and RCPCH. 2017. Im Internet: https:// www.rcr.ac.uk/publication/radiological-investigation-suspected-physi cal-abuse-children; Stand 15.7.2019

[8] Arbeitsgemeinschaft der Wissenschaftlichen Medizinischen Fachgesellschaften e. V. (AWMF). S1-Leitlinie 064/014 -Verdacht auf Misshandlung -Bildgebende Diagnostik. Im Internt: https://www.awmf.org/leitlinien/ detail/II/027-069/II-ansicht/inhalt.html; Stand 15.7.2019

[9] Phillips KL, Bastin ST, Davies-Payne D et al. Radiographic skeletal survey for non-accidental injury: systematic review and development of a national New Zealand protocol. J Med Imaging Radiat Oncol 2015; 59: 5465. doi:10.1111/1754-9485.12271

[10] https://www.awmf.org/uploads/tx_szleitlinien/027-069m_S3_Kindes misshandlung-missbrauch-vernachlaessigung-Kinderschutzleitlinie_ 2019-02.pdf

[11] Royal College of Paediatrics and Child Health 2017. Child Protection Evidence Systematic review on Neurological Injuries. Cardiff University Im Internt: https://www.rcpch.ac.uk/sites/default/files/2018-07/child_pro tection_evidence_-_neurological_injuries.pdf; Stand 15.7.2019

[12] Lindberg DM, Berger RP, Reynolds MS et al. Yield of Skeletal Survey by Age in Children Referred to Abuse Specialists. J Pediatr 2014; 164: 1268 1273. doi:10.1016/j.jpeds.2014.01.068

[13] Maguire S, Cowley L, Mann M et al. What does the recent literature add to the identification and investigation of fractures in child abuse: an overview of review updates 2005-2013. Evid-Based Child Health 2013; 8: 2044-2057. https://doi.org/10.1002/ebch.1941

[14] Royal College of Paediatrics and Child Health 2017. Child Protection Evidence Systematic review on Fractures Last updated: February 2015. Im Internet: https://www.rcpch.ac.uk/resources/child-protection-evi dence-fractures; Stand 15.7.2019

[15] Lindberg DM, Shapiro RA, Laskey AL et al. Prevalence of abusive injuries in siblings and household contacts of physically abused children. Pediatrics 2012; 130: 193-201. doi:10.1542/peds.2012-0085

[16] Perez-Rossello JM, Connolly SA, Newton AW et al. Whole-body MRI in suspected infant abuse. Am J Roentgenol 2010; 195: 744-750. doi:10.2214/Am J Roentgenol.09.3364

[17] Darge K, Jaramillo D, Siegel MJ. Whole-body MRI in children: Current status and future applications. EJR 2008; 68: 289-298. doi:10.1016/ j.ejrad.2008.05.018

[18] Jha P, Stein-Wexler R, Coulter K et al. Optimizing bone surveys performed for suspected non-accidental trauma with attention to maximizing diagnostic yield while minimizing radiation exposure: utility of pelvic and lateral radiographs. Pediatr Radiol 2013; 43: 668-672. doi:10.1007/s00247-012-2614-9

[19] Karmazyn B, Lewis ME, Jennings SG et al. The prevalence of uncommon fractures on skeletal surveys performed to evaluate for suspected abuse in 930 children: should practice guidelines change? Am J Roentgenol 2011; 197: W159-W163. doi:10.2214/Am J Roentgenol.10.5733 
[20] Kleinman PK, Morris NB, Makris ] et al. Yield of radiographic skeletal surveys for detection of hand, foot, and spine fractures in suspected child abuse. Am J Roentgenol 2013; 200: 641-644. doi:10.2214/Am J Roentgenol.12.8878

[21] Powell-Doherty RD, Raynor NE, Goodenow DA et al. Examining the role of follow-up skeletal surveys in non-accidental trauma. Am J Surg 2017; 213: 606-610. doi:10.1016/j.amjsurg.2016.12.004

[22] Harper NS, Eddleman S, Lindberg DM et al. The utility of follow-up skeletal surveys in child abuse. Pediatrics 2013; 131: e672-e678. doi:10.1542/peds.2012-2608
[23] Harper NS, Lewis T, Eddleman S et al. Follow-up skeletal survey use by child abuse pediatricians. Child Abuse Negl 2016; 51: 336-342. doi:10.1016/j.chiabu.2015.08.015

[24] Karmazyn B, Wanner MR, Marine MB et al. The added value of a second read by pediatric radiologists for outside skeletal surveys. Pediatr Radiol 2019; 49: 203-209. doi:10.1007/s00247-018-4276-8 